\title{
Transforaminal Insertion of a Thermocouple on the Posterior Vertebral Wall Combined with Hydrodissection during Lumbar Spinal Radiofrequency Ablation
}

\author{
(D) Lecigne, (D). Garnon, (D).L. Cazzato, (DP. Auloge, (DD. Dalili, (D) G. Koch, and (D) A. Gangi
}

\begin{abstract}
SUMMARY: The purpose of the present article is to describe the technique of transforaminal insertion of an ultrathin thermosensor in the anterior epidural space in 13 patients treated by radiofrequency ablation. The mean time taken to position the thermosensor was 10.6 minutes (range, 5-38 minutes). Technical success was 93\% (correct positioning in 13/14 levels). Additional hydrodissection was performed through the same access in 11 cases. No postoperative neural deficit was elicited in any of the cases.
\end{abstract}

ABBREVIATION: RFA = radiofrequency ablation

nadvertent thermal ablation of neural structures located in the lumbar canal is a rare but potentially debilitating complication following percutaneous thermal ablation of lesions located in the vertebral body, if the expected ablation zone abuts the posterior wall of the vertebra. ${ }^{1-3}$ Using a thermosensor, one can monitor local temperatures to ensure that threshold temperatures are not breached in a critical area. ${ }^{4,5}$ However, precise positioning of the thermometer at an ideal interface between the lumbar spine and the dural sac can be challenging. We herein aim to describe the technique of transforaminal insertion of an ultrathin thermocouple into the anterior epidural space while performing radiofrequency ablation of spinal metastases to monitor the temperature at the interface between the posterior part of the vertebral body and the dura.

\section{MATERIALS AND METHODS}

This is a single-center retrospective study. All patients gave informed consent for the procedure. Institutional review board approval was waived.

Received May 31, 2019; accepted after revision August 1.

From the Department of Radiology (R.L.), Pôle d'imagerie, Centre Hospitalier Universitaire, Cedex, France; Department of Interventional Radiology (J.G., R.L.C., P.A., G.K., A.G.), Hopitaux Universitaires de Strasbourg, Strasbourg, France; and Department of Radiology and Radiological Science (D.D.), Johns Hopkins University School of Medicine, Baltimore, Maryland.

Please address correspondence to Lecigne Romain, Department of Radiology, Pôle d'imagerie, Centre Hospitalier Universitaire, 47 rue Cognacq Jay, 51092 Reims Cedex, France; e-mail: romainlecigne@hotmail.fr

http://dx.doi.org/10.3174/ajnr.A6233

\section{Study Population and Procedures}

Between April 2015 and August 2018, thirteen patients (7 women, 6 men; mean age, 60.8 years) with 14 lumbar tumors were treated in our institution using radiofrequency ablation (RFA) and associated planned local temperature monitoring using the transforaminal approach. Patient, lesion, and RFA characteristics are listed in Table 1.

All procedures were performed with the patient under general anesthesia in the prone position, with either conebeam CT guidance ( $n=7$ patients) or combined CT and fluoroscopic guidance $(n=1)$, depending on room availability at the time of treatment. Thermal ablation was conducted according to the manufacturer's recommendations. If the temperature exceeded $45^{\circ}$ and was not controllable with active hydrodissection, RFA was stopped. After completion of the ablation, additional cementoplasty was performed to ensure bone consolidation and reduce the risk of secondary postablation fracture.

\section{Technique of the Double-Oblique Transforaminal Approach}

Optimal insertion of the thermometer requires a doubleoblique approach; the ideal trajectory is from cranial to caudal and from lateral to medial (Figs 1 and 2). First, an 18-ga spinal needle is advanced in the very medial part of the foramen. Subsequently, a 20-cm-long, 28-ga reusable monopolar nitinol radiofrequency electrode (MultGen; Stryker, Kalamazoo, Michigan) is inserted coaxially through the spinal needle and gently advanced. Although little resistance can be felt, the electrode should be advanced until it reaches the posterior vertebral wall/posterior part of the tumor. The electrode is used only for its capacity to display the temperature (and is 
Table 1: Patients, lesions, and RFA characteristics

\begin{tabular}{|c|c|c|c|c|c|c|c|}
\hline Patient & $\begin{array}{l}\text { Age } \\
\text { (yr) }\end{array}$ & $\begin{array}{l}\text { Primary } \\
\text { Cancer }\end{array}$ & $\begin{array}{l}\text { Lesion } \\
\text { No. }\end{array}$ & Level & $\begin{array}{l}\text { Posterior Cortex } \\
\text { Disruption }\end{array}$ & $\begin{array}{c}\text { Epidural } \\
\text { Involvement }\end{array}$ & RFA Type (Device, Company) \\
\hline 1 & 55 & Colon & 1 & L1 & No & No & Bipolar RFA (OsteoCool; Medtronic) ${ }^{a}$ \\
\hline 2 & 78 & Bladder & 1 & L2 & No & No & Bipolar RFA (OsteoCool; Medtronic) \\
\hline 3 & 46 & Breast & 1 & L1 & No & No & Monopolar RFA (Cool-tip; Medtronic) \\
\hline 4 & 66 & Kidney & 1 & L2 & No & Yes & Bipolar RFA (OsteoCool; Medtronic) \\
\hline \multirow[t]{2}{*}{5} & 52 & Breast & 1 & L3 & No & No & Bipolar RFA (OsteoCool; Medtronic) \\
\hline & & & 2 & L4 & No & No & Bipolar RFA (OsteoCool; Medtronic) \\
\hline 6 & 73 & Lung & 1 & L1 & No & No & Bipolar RFA (STAR; Merrit Medical) ${ }^{\mathrm{b}}$ \\
\hline 7 & 70 & Melanoma & 1 & L1 & No & Yes & Bipolar RFA (OsteoCool; Medtronic) \\
\hline 8 & 76 & Lung & 1 & L2 & Yes & Yes & Bipolar RFA (OsteoCool; Medtronic) \\
\hline 9 & 64 & Breast & 1 & L1 & No & No & Bipolar RFA (OsteoCool; Medtronic) \\
\hline 10 & 63 & Lung & 1 & L4 & No & No & Bipolar RFA (OsteoCool; Medtronic) \\
\hline 11 & 67 & Rectum & 1 & L3 & No & No & Bipolar RFA (OsteoCool; Medtronic) \\
\hline 12 & 41 & Lung & 1 & L1 & No & No & Bipolar RFA (OsteoCool; Medtronic) \\
\hline 13 & 40 & Breast & 1 & L3 & Yes & Yes & Bipolar RFA (OsteoCool; Medtronic) \\
\hline
\end{tabular}

${ }^{a}$ Medtronic, Minneapolis, Minnesota.

${ }^{\mathrm{b}}$ Merit Medical, South Jordan, Utah.

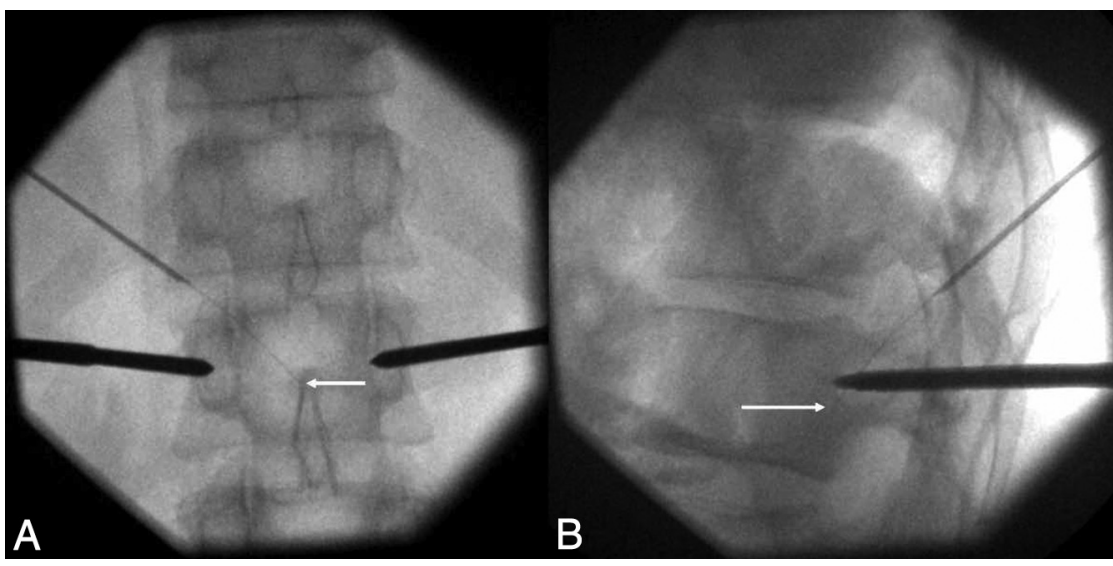

FIG 1. Double-oblique transforaminal approach on fluoroscopy (patient 12). Anterior-posterior $(A)$ and lateral $(B)$ fluoroscopic projections demonstrate the tip of the thermosensor (white arrow) just posterior to the vertebral body, at its mid portion $(B)$, and in the midline $(A)$, thanks to an oblique approach in both anterior-posterior and lateral views.

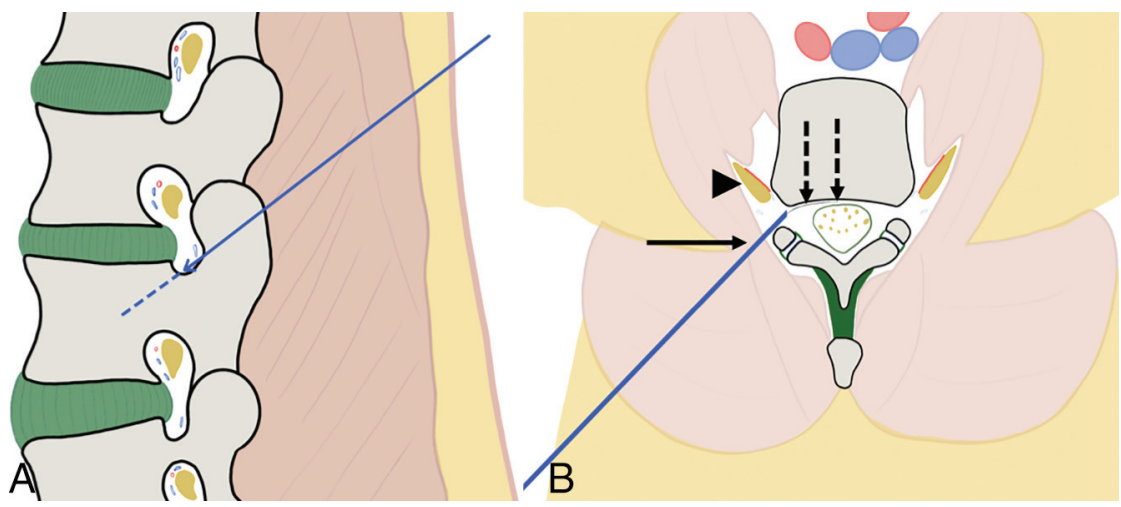

FIG 2. Representation and principle of the double-oblique approach. A, Drawing from a sagittal perspective. The craniocaudal approach in the sagittal plane enables going through the posterior and inferior parts of the foramen, away from the radicular nerve and vessels. $B$, Drawing from an oblique axial view (in the axis of the sagittal angulation). The lateromedial approach allows slipping along the facet joint with the 18-ga needle (arrow), away from the nerve and vessels (arrowhead). The 28-ga thermosensor (dotted arrows) can then be advanced into the anterior epidural space toward the posterior wall of the vertebral body. therefore referred to as a thermosensor). The various steps of the double-oblique transforaminal approach are presented in Fig 3.

Additionally, hydrodissection using dextrose mixed with contrast (50:50 ratio for optimal visualization) can be combined with temperature monitoring. Here, before the insertion of the thermosensor, a Y-valve is connected to the hub of the 18-ga needle, and once the thermosensor has been introduced through the distal port of the valve, fluid may be injected through the lateral port (Fig 4).

\section{RESULTS}

Detailed results are listed in Table 2. The mean time to optimally position the thermosensor was 10.6 minutes (range, 5-38 minutes). There was a single case requiring $>12$ minutes for thermosensor insertion (a case requiring conebeam CT acquisition). Optimal positioning was achieved in 13 cases with a technical success rate of $93 \%$. In the case considered unsuccessful, the thermometer was in the epidural space but $4 \mathrm{~mm}$ cranial and $5 \mathrm{~mm}$ lateral to the optimum, desired end point. Additional hydrodissection was performed through the same access in 11 cases and was effective in all cases except 2 (both cases with epidural extension). The mean maximal temperature displayed by the thermosensor was $42^{\circ}$ (range, $39^{\circ}-45^{\circ}$ ). None of the cases had premature stoppage of ablation. In a single case 


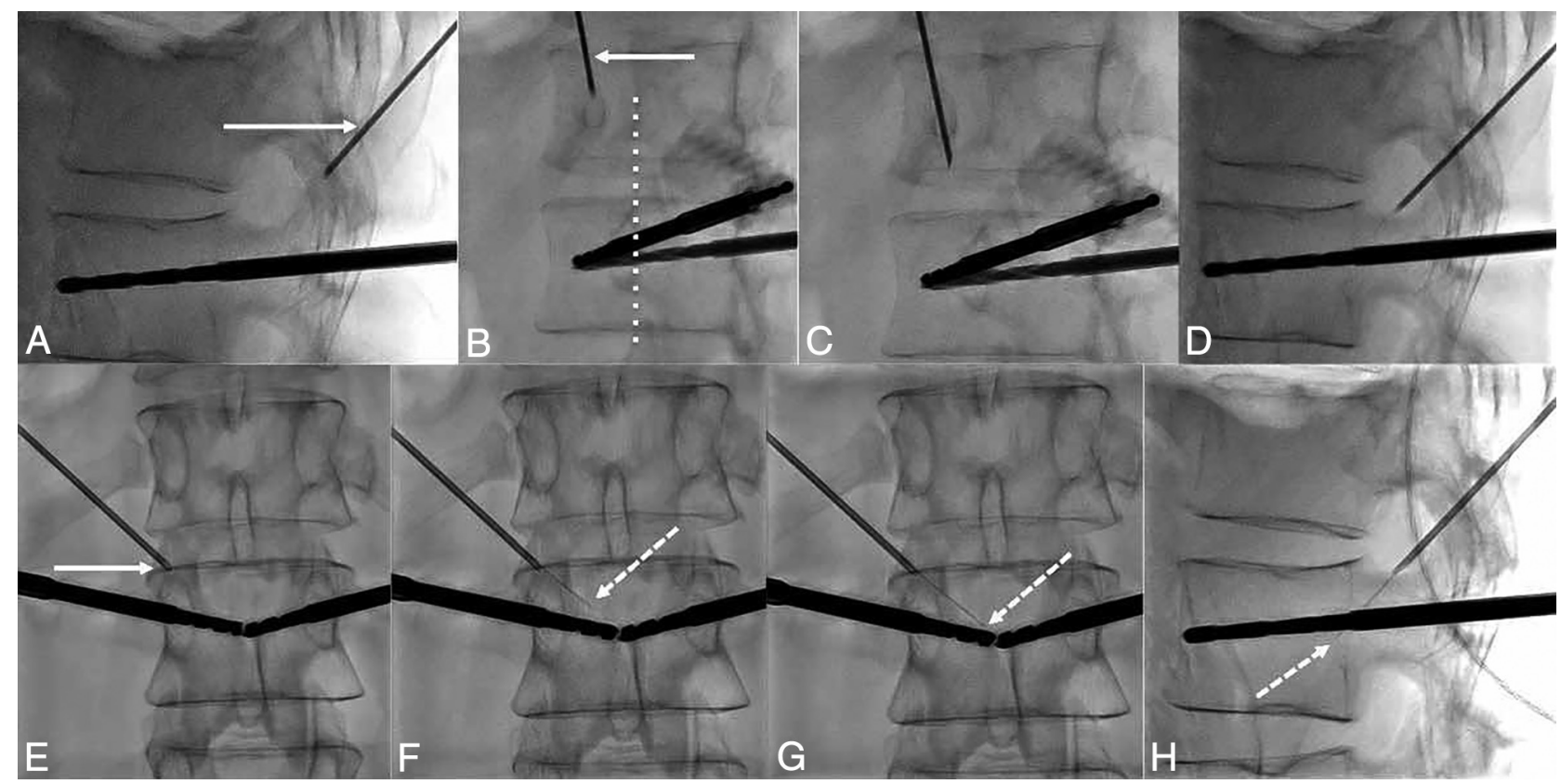

FIG 3. Fluoroscopic details of the technique of the transforaminal approach. $A$, The craniocaudal angulation in the sagittal plane is estimated on the lateral projection to point the 18-ga needle (white arrow) used as a landmark on the skin of the patient toward the posterior and inferior parts of the foramen. $B$, The $35^{\circ}$ oblique view (from the anterior-posterior view) is then used to define the distance of the entry point laterally. The 18-ga spinal needle (arrow) should be pointed toward the lateral part of the facet joint (dotted line). $C$, The needle is advanced in the oblique view toward the foramen. $D$, Once in the vicinity of the foramen, the lateral view confirms that the needle enters it at its posterior and inferior parts. E, Satisfactory localization of the needle tip (arrow) inside the foramen is confirmed on anterior-posterior projection. $F$, The 28-ga thermosensor (dotted arrow) is gently advanced into the canal until it reaches the midline (G), where resistance is felt. $H$, At this point, the tip of the thermometer (dotted arrow) should be located at the middle portion of the vertebral body on the lateral view.

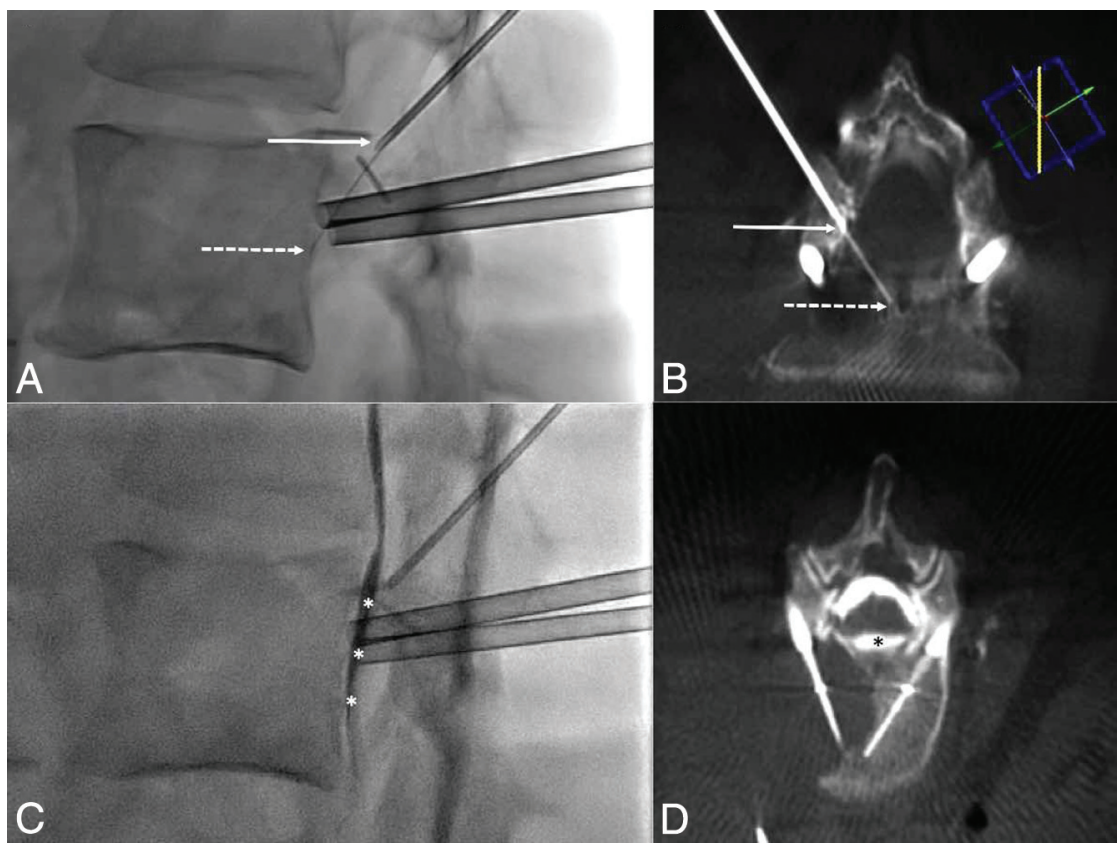

FIG 4. Thermal monitoring combined with hydrodissection. A, Lateral fluoroscopic view demonstrates the 18-ga needle in the foramen (arrow) and the thermosensor in contact with the posterior wall (dotted arrow). B, Conebeam CT acquisition with reconstruction in the axis of the needle and thermometer confirms the findings of fluoroscopy with the 18-ga needle (arrow) and the thermosensor (dotted arrow). C, Lateral view after injection of dextrose mixed with contrast shows satisfactory diffusion of the fluid into the anterior epidural space (white asterisks) separating the dural sac from the vertebral body. D, This is again outlined on the conebeam CT acquisition, which demonstrates the hydrodissection (black asterisk) between the posterior wall and the dural sac. (performed with monopolar RFA), continuous irrigation of the anterior epidural space had to be performed to maintain the temperature at $45^{\circ}$. No postoperative neural deficits were encountered. MR imaging was performed in the early postoperative period in all patients within a mean of 13 days (range, 1-30 days) with no evidence of epidural hematoma, and fluid had completely reabsorbed in all patients who had benefited from additional hydrodissection.

\section{DISCUSSION}

As demonstrated in this case series, the transforaminal insertion of a small thermosensor into the anterior epidural space at the midlevel of a vertebral body is technically feasible, can be performed with stand-alone fluoroscopy, and adds little time to the procedure. Double-oblique access is mandatory to access the midlevel of the vertebral body wall because it allows lining up of the thermosensor with the ideal trajectory. Because the thermocouple is very thin, a more direct approach 


\begin{tabular}{|c|c|c|c|c|c|c|c|}
\hline Patient & Foramen & Guidance & $\begin{array}{l}\text { Time } \\
(\min )\end{array}$ & $\begin{array}{l}\text { Obliquity in the } \\
\text { Sagittal Plane }\end{array}$ & Technical Success $^{a}$ & Hydrodissection & $\begin{array}{c}\text { Maximal } \\
\text { Temperature }\left({ }^{\circ} \mathrm{C}\right) \\
\end{array}$ \\
\hline 1 & $\mathrm{~T} 12-\mathrm{L} 1$ & Fluoro & 11 & $40^{\circ}$ & Yes & Yes, effective & 39 \\
\hline 2 & L1-L2 & Fluoro & 11 & $40^{\circ}$ & Yes & Yes, effective & 41 \\
\hline 3 & T12-L1 & CT \& fluoro & 9 & $36^{\circ}$ & Yes & Yes, effective & 45 \\
\hline 4 & L1-L2 & Fluoro & 12 & $35^{\circ}$ & Yes & No & 45 \\
\hline \multirow[t]{2}{*}{5} & L2-L3 & Fluoro & 10 & $43^{\circ}$ & Yes & Yes, effective & 43 \\
\hline & L3-L4 & Fluoro & 6 & $38^{\circ}$ & Yes & No & 44 \\
\hline 6 & T12-L1 & CT \& fluoro & 7 & $42^{\circ}$ & Yes & Yes, effective & 41 \\
\hline 7 & T12-L1 & Fluoro & 8 & $44^{\circ}$ & Yes & Yes, ineffective & 44 \\
\hline 8 & L1-L2 & Fluoro \& CBCT & 38 & $33^{\circ}$ & $\begin{array}{l}\text { No ( } 4 \mathrm{~mm} \text { too cranial and } \\
5 \mathrm{~mm} \text { too lateral) }\end{array}$ & Yes, ineffective & 39 \\
\hline 9 & T12-L1 & Fluoro & 5 & $36^{\circ}$ & Yes & Yes, effective & 43 \\
\hline 10 & L3-L4 & Fluoro & 8 & $47^{\circ}$ & Yes & Yes, effective & 38 \\
\hline 11 & L2-L3 & CT \& fluoro & 9 & $37^{\circ}$ & Yes & Yes, effective & 39 \\
\hline 12 & T12-L1 & CT \& fluoro & 7 & $47^{\circ}$ & Yes & Yes, effective & 45 \\
\hline 13 & L2-L3 & CT \& fluoro & 7 & $44^{\circ}$ & Yes & No & 42 \\
\hline
\end{tabular}

Note:-Fluoro indicates fluoroscopy; CBCT, conbeam CT.

${ }^{a}$ Technical success was defined by a position of the thermosensor in the midline on anteroposterior view and at the midportion of the posterior wall on lateral view.

(similar to a discal puncture) cannot achieve such positioning because the thermometer will not "take the curve" along the posterior part of the vertebral body. The craniocaudal approach should always be favored to avoid transgressing the danger zone located at the anterior and superior parts of the foramina, which contains the radicular nerve and adjacent vessels. ${ }^{6}$ The doubleoblique approach allows the safest passage (posterior and inferior) through the foramen. ${ }^{7.8}$ In the aging spine, the anatomy of the foramen can, however, be modified by a bulging disc and/or osteophytes. Careful examination of the planning CT is therefore recommended before thermosensor insertion.

Although more challenging than a posterior epidural or a straight transforaminal approach, the technique is the only method to access the anterior epidural space at exactly the level of the RFA probes where fluctuations in local temperature are believed to be the most critical because of the shape and extent of the expected ablation zone. Moreover, it can easily be combined with hydrodissection, which allows separation of the dural sac from the ablation area if the tumor does not extend into the anterior epidural fat. The major challenge of the technique is to precisely navigate through the foramen under fluoroscopy with a double-oblique approach. Any deviation from the ideal trajectory might lead to either a suboptimal position or the impossibility of advancing the thermosensor because of bony interposition.

In this series, we had a single case in which active fluid injection was required to maintain the local temperature at a maximum threshold of $45^{\circ}$. This excellent safety profile of ablation might be explained by the preferential use of dedicated bone bipolar RFA devices that are known not to diffuse through an intact osseous cortex and form smaller, precise, and more predictable ablation zones than other ablation techniques (cryoablation, microwave, monopolar RFA). ${ }^{2,9}$ Nevertheless, local thermal monitoring gives extra confidence and reassurance to the operating physician who can follow the real-time evolution of local temperatures, thereby increasing the safety profile of the procedure, even though the present study is not powered enough to statistically prove it. This technique is particularly useful if the procedure is being performed with the patient under general anesthesia without access to intraprocedural neurophysiologic testing to monitor neural conduction. ${ }^{10}$ It can theoretically be used in combination with all heat- or cold-based ablation modalities (RFA, microwave, laser, cryoablation) to avoid breaching above $45^{\circ}$ or below $0^{\circ}$, which are known to be the neurotoxic threshold temperatures. ${ }^{11}$ Although favorable and with many potential uses, this technique is unfortunately not transferable to the dorsal spine because of the interposition of the ribs, which preclude a required steeper sagittal approach. The present study is limited by the small cohort of patients, which does not allow definitive conclusions regarding efficacy and safety. Moreover, all the procedures were performed by interventional radiologists trained in the spinal procedure, likely representing a bias in terms of reproducibility.

Disclosures: Julien Garnon—UNRELATED: Consultancy: BTG-Galil Medical; Payment for Lectures Including Service on Speakers Bureaus: Canon Medical, Medtronic. Afshin Gangi-UNRELATED: Payment for Lectures Including Service on Speakers Bureaus: Canon Medical; Patents (Planned, Pending or Issued): AprioMed.

\section{REFERENCES}

1. Khan MA, Deib G, Deldar B, et al. Efficacy and safety of percutaneous microwave ablation and cementoplasty in the treatment of painful spinal metastases and myeloma. AJNR Am J Neuroradiol 2018;39:1376-83 CrossRef Medline

2. Wallace AN, Hillen TJ, Friedman MV, et al. Percutaneous spinal ablation in a sheep model: protective capacity of an intact cortex, correlation of ablation parameters with ablation zone size, and correlation of postablation MRI and pathologic findings. AJNR Am J Neuroradiol 2017;38:1653-59 CrossRef Medline

3. Westbroek EM, Goodwin ML, Hui F, et al. Thermal injury to the spinal cord, a rare complication of percutaneous microwave spine tumor ablation: case report. J Clin Neurosci 2019;64:50-54 CrossRef Medline

4. Tsoumakidou G, Buy X, Garnon J, et al. Percutaneous thermal ablation: how to protect the surrounding organs. Tech Vasc Interv Radiol 2011;14:170-76 CrossRef Medline

5. Kastler A, Krainik A, Sakhri L, et al. Feasibility of real-time intraprocedural temperature control during bone metastasis thermal 
microwave ablation: a bicentric retrospective study. J Vasc Interv Radiol 2017;28:366-71 CrossRef Medline

6. Hoshide R, Feldman E, Taylor W. Cadaveric analysis of the Kambin's triangle. Cureus 2016;8:e475 CrossRef Medline

7. Mandell JC, Czuczman GJ, Gaviola GC, et al. The lumbar neural foramen and transforaminal epidural steroid injections: an anatomic review with key safety considerations in planning the percutaneous approach. AJR Am J Roentgenol 2017;209:W26-35 CrossRef Medline

8. Kennedy DJ, Dreyfuss P, Aprill CN, et al. Paraplegia following image-guided transforaminal lumbar spine epidural steroid injection: two case reports. Pain Med 2009;10:1389-94 CrossRef Medline

9. Cazzato RL, Garnon J, Caudrelier J, et al. Low-power bipolar radiofrequency ablation and vertebral augmentation for the palliative treatment of spinal malignancies. Int J Hyperthermia 2018;34:128288 CrossRef Medline

10. Kurup AN, Schmit GD, Morris JM, et al. Avoiding complications in bone and soft-tissue ablation. Cardiovasc Intervent Radiol 2017; 40:166-76 CrossRef Medline

11. Tsoumakidou G, Koch G, Caudrelier J, et al. Image-guided spinal ablation: a review. Cardiovasc Intervent Radiol 2016;39:1229-38 CrossRef Medline 